2016-10-26

\title{
Supervision of Students in Social Care Education: Practice Teachers' Views of Their Role
}

Fiona McSweeney

Technological University Dublin, fiona.mcsweeney@tudublin.ie

Follow this and additional works at: https://arrow.tudublin.ie/aaschlanart

Part of the Higher Education Commons

\section{Recommended Citation}

McSweeney, F. (2016). Supervision of students in social care education: practice teachers' views of their role. Social Work Education: The International Journal, October 26th. 2016. doi:10.1080/

02615479.2016 .1249837

This Article is brought to you for free and open access by the Languages at ARROW@TU Dublin. It has been accepted for inclusion in Articles by an authorized administrator of ARROW@TU Dublin. For more information, please contact arrow.admin@tudublin.ie, aisling.coyne@tudublin.ie,gerard.connolly@tudublin.ie.

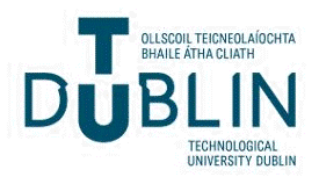




\title{
Supervision of Students in Social Care Education: Practice Teachers' Views of their Role
}

\begin{abstract}
This paper presents findings from research exploring how practice teachers in social care education in Ireland view their role, in particular what elements they prioritise and what they see as relatively unimportant. Q methodology was used to compare the participants' viewpoints. Twenty practice teachers, from varying practice backgrounds and levels of experience, sorted statements outlining aspects of the practice teacher's role, during individual interviews. Analysis indicates two ways of conceptualising the role. One focuses within the agency, prioritising students' awareness of the clients using the social care service and policies as guiding practice. The second encapsulates a broader view of learning beyond the agency, focusing on the practice teacher assisting the student to integrate theory with practice and using reflection as a learning tool.
\end{abstract} Conclusions are drawn in relation to social care education.

Keywords: supervision; social care students; practice teacher role; practice placement; clients; policies; reflection; theory; Q methodology

\section{Context}

Social care work is defined as 'the professional provision of care, protection, support, welfare and advocacy for vulnerable or dependent clients, individually or in groups.' (Joint Committee on Social Care Professionals, 2003, p.13). Social care workers are employed in residential care for young people, day and residential services for individuals with intellectual disabilities, people with sensory impairments, mental health issues, youth work, services for people who are homeless, family support services and addiction services.

In Ireland, social care education involves completing a three or four year degree programme of academic modules and practice placements to meet standards set down by Qualifications and Quality Ireland (Social Care Work Award Standards, 2014). Placements are considered to be an essential part of the education and preparation for practice in social care work. Students must complete between 800 and 1000 hours on placement in a variety of 
social care settings throughout the educational programme and they must pass this element of the programme. To maximise the student's learning while on placement $\mathrm{s} / \mathrm{he}$ is appointed a supervisor or practice teacher who is expected to agree learning objectives with the student, conduct regular supervision sessions to support and monitor the student's learning, and liaise with the college (Irish Association of Social Care Educators, 2009). Although, as noted by Davys and Beddoe (2000), there is not consensus on the title of the person in an agency who is in charge of the student on placement, the role essentially involves managing, assessing, monitoring, teaching, challenging and supporting the student. Citing Ford and Jones (1987) they capture the complexity of the role of the supervisor/practice teacher with responsibilities to clients, agency and standards of the service provided along with guaranteeing the students' opportunities to learn. Thus practice teachers are essential in the education of social care workers (Simpson, Mathews \& Crawford, 2014). Due to the complexity of the role of the practice teacher and the centrality of them to the education of social care students the aim of the research reported here was to explore similarities and differences in how practice teachers in social care education view their role and behaviours they prioritised. Due to some similarities between social work and social care work (Engelberg \& Limbach-Reich, 2015), as well as the lack of research specific to social care practice, the literature reviewed includes that in relation to social work.

\section{Practice Teacher Role}

Lefevre (2005) suggests that the practice teacher educates through 'direct teaching; facilitating learning; modelling good practice; assisting with linking theory and practice' (p.566). The practice placement manual of the Irish Association of Social Care Educators (2009) emphasises the part of placement for assisting the student to integrate theoretical knowledge with practice and some research supports its importance. Tsien and Tsui (2007, p. 349) suggest that the 
'ultimate goal of practice teaching is to produce a practitioner who can integrate theory and practice sensitively, systematically and successfully.' Theoretical knowledge is important as it provides students with 'a framework to understand what they are doing' (Fortune \& Kaye, 2003, p.24). Students have been found to express satisfaction when practice teachers make links between practice and theoretical frameworks (Fortune, McCarthy \& Abramson, 2001; Bogo, 2006) and are aware of what the student is learning in college (Knight, 2001). However the social work students in Wilson, Walsh and Kirby's (2007) study rated organisational policies and procedures as higher in guiding their practice than social work theory. It has been noted that practice teachers can be disconcerted by the prospect of assisting students to link theory and practice. This is suggested to be due to practitioners sometimes viewing theory as being separate from everyday practice, instead being something that is learned from books or having lost conscious awareness of the theoretical underpinnings of their practice (Fisher \& Somerton, 2000; Higgins, 2014). The complexity of social welfare work and busyness of the workplace is also offered as an explanation (Dettlaff \& Wallace, 2003).

Staempfli, Kunz and Tov (2012) explain experienced practitioners' difficulty in naming knowledge is due to it being subconscious, as successful practice in pressurised situations requires fast thinking. Conversely Homonoff (2008), from interviewing ten social work practice teachers, found that they had a good knowledge of social work theory and reported that students had difficulty integrating theory with practice as they did not always see theory learned in college as being useful for practice. Congruent with this are findings of a survey of practice teachers $(\mathrm{n}=144)$ who 'felt students were taught 'out-of-date' theories' (Clapton et al., 2006, p.647). Homonoff's (2008) research draws attention to the variety of theoretical frameworks that can be used to underpin practice, which can make it difficult for busy practitioners to keep themselves updated with developments in theory and research (Clapton et al., 2006). This is supported by a survey of 71 practice teachers in social work who showed 
little commonality among theories they used to guide their practice (Forte \& LaMade, 2011). Higgins (2014, p.72) concludes, from his research with practice teachers and academics in social work education, that the university and the practice setting work from different pedagogical approaches. The former emphasises 'a critical engagement with learning' and the latter focuses 'on getting work done.' Tierney (2011) suggests that the model of supervision used can affect the separation or integration of academic and practice learning while Miehls, Everett, Segal and du Bois (2013) recommend that colleges provide resources and course syllabi to help practice teachers be aware of what the student is learning in college to aid theory/practice integration. However, despite focusing on integrating academic content taught with fieldwork, through communication with placement agencies, Savaya, Peleg-Oren, Stange and Geron (2003, p.305) found academic instructors and placement practice teachers in Israel prioritised different aims and missions in social work training. The latter group prioritised knowledge of social policies and social work values, intervention skills as well as 'ethical obligations and emotional capacities', relevant to the delivery of services, while the former prioritised social work ideologies. Associated with ethical obligations is the part of values in training for the social professions.

\section{Values and Modelling}

Thompson (2006) emphasises the importance of social work training to be embedded in values such as a non-judgemental attitude towards clients and the clients' right to selfdetermination. Through modelling good practice and facilitating students' awareness of their own value systems practice teachers can help ensure that practice fits with professional values. Fortune and Kaye (2003) found that practice teachers discussing students' emotional and cognitive reactions to their practice was correlated with student satisfaction with their placement. While modelling good practice is appreciated by students (Spence, Wilson, 
Kavanagh, Strong \& Worrall, 2001; Fortune et al., 2001; Bogo, 2006) and contributes to motivation (Fortune et al., 2005) the ability to model good practice in a way that assists students' learning is reported to be dependent on the number of students a practice teacher is supervising (Wilson, O’Conner, Walsh \& Kirby, 2009). Also students report that identification with a practice teacher who models good practice helps them develop their own professional identity as a practitioner (Miehls, et al., 2013). Identification with and learning from the practice teacher is found to be influenced by the quality of the relationship.

\section{Relationship}

Brodie and Williams (2013), from interviews with eight social work students and eight practice teachers, found that the practice teacher being non-judgemental, approachable, reliable and honest is viewed as important. These characteristics enable students to 'open up' in supervision sessions (Abbott \& Lyter, 1999). Students also value a practice teacher who shows interest in their learning and encourages the exchange of viewpoints (Knight, 2001). Students who had experienced a poor relationship with their practice teacher in the Wilson et al. (2009, p.638) study reported it impacting on their 'self-confidence and ability to articulate my learning' as well it causing them not to be completely honest with the practice teacher. Knight (2010) also points out the importance of a good relationship so that the student is comfortable discussing any indirect trauma as a consequence of working with survivors of abuse. If students experience the placement setting as supportive and inclusive they 'are more ready to participate in daily practice and will be more open to learning' (Vågstǿl \& Skǿien, 2011, p.72) and 'feel free to struggle, learn and grow to their potential' (Karpenko \& Gidycz, 2012). A good relationship is also important for students to 'receive and use critical feedback about their practice' (Bogo, 2006, p.178). However the research presents competing views about critical feedback. 


\section{Feedback}

Students have also been reported to value and are motivated by performance specific feedback on their practice (Fortune et al., 2001; Fortune, Cavazos \& Lee, 2005), particularly when it is constructive, balanced and can be applied to practice (Bogo, 2006; Spence et al., 2001) and is considered to be 'honest' (Brodie \& Williams, 2013). This helps the student become more selfaware and recognise both positive aspects of his/her practice, thus increasing self-efficacy, as well as areas for improvement. Miehls et al., (2013), from focus groups conducted with twentyone social work students, found that students wanted more constructive criticism of both their practice and their feelings towards clients. Abbott and Lyter (1999) report that social work students valued criticism of their practice more than practice teachers. They suggest that criticism is more effective when balanced with positive feedback, students are prepared for it, learning goals are established and students are encouraged to identify their own strengths and weaknesses. Knight (2001) found that social work students particularly valued activities towards the end of their placements that facilitated them in being self-critical in line with one of the aims of the practice placement being for the student to develop 'critical self-awareness' (Irish Association of Social Care Educators, 2009, p.7). However practice teachers can be uncomfortable giving negative feedback to students as it conflicts with their professional values of being non-judgemental and focusing on strengths and their 'professional self-image as caring and accepting' (Bogo, Regehr, Power and Regehr, 2007 p.112). They also found that practice teachers feel that having to regularly critique the practice of their students damaged the supervisory relationship. The relationship between student and practice teacher has also been report to impact on how the student's practice is evaluated with poor rapport between them sometimes associated with lenient evaluation (Karpenko \& Gidycz, 2012). They suggest this is worrying as practice teachers can be viewed as gatekeepers to the profession. As students learn through feedback they also learn through reflection and the opportunity to practice skills. 


\section{Reflection}

Encouraging students to reflect on their practice is considered fundamental to practice teaching in social care work (O’Neill, 2009; Irish Association of Social Care Educators, 2009). Staempfli et al., (2012, p.64) argue that reflection is an essential link between theory and practice and that 'evidence-based practice needs to be combined with reflexivity' to produce 'best practice.' Student social workers report finding reflective learning difficult but very beneficial (Halton, Murphy \& Dempsey, 2007). In another survey of 139 social work students, $61 \%$ of the sample rated the opportunities to develop their reflective practice skills on placement as satisfying (Wilson et al., 2007), suggesting that it is not always the priority of all practice teachers. On the other hand Homonoff's (2008) practice teacher participants valued students' reflection on their practice and noted the importance of creating a safe space in supervision to facilitate it.

\section{Skills and Development}

Fortune, Lee and Cavazos (2007) propose that practice placements provide opportunities for students to practise professional skills such as empathetic listening and implementing interventions. They found, from a survey of 188 social work students, that opportunities to practise professional skills was associated with students' self-ratings and practice teachers' ratings of student competency. Students may differ in their skill levels so awareness of the developmental level of the student is important (Karpenko \& Gidycz, 2012) so that her or his learning is appropriately scaffolded (Nye, 2007). While practice teachers expect that students are able to talk about their own learning needs (Simpson et al., 2014), students see collaborative goal setting as one of the elements of good supervision (Miehls, et al., 2013) and like to work with the practice teacher to develop a learning contract in which 'expectations and responsibilities have been clearly identified' (Davys and Beddoe, 2010 p. 
444). Students also appreciate a balance between being supervised and being autonomous (Miehls et al., 2013) as well as a balance between being supported and challenged with tasks so practice teachers assign 'them the work they most want - and the work they least want' (Homonoff, 2008, p.152). At the beginning of the placement students also value activities that introduce them to the setting, its policies and procedures (Miehls et al., 2013) and are told what is expected of them (Knight, 2001).

\section{Benefits to the Agency}

Providing a placement for students in an agency has also been reported to aid the learning of the practice teacher and other staff (Raschick, 1998; Globerman \& Bogo, 2003), in particular increasing the practice teacher's reflection; bringing new ideas and knowledge; challenging practice and aiding in understanding the learning process (Globerman \& Bogo, 2003; Barton, Bell \& Bowles, 2005).

\section{Summary}

In conclusion existing research on students and practice teachers' views of the role of the practice teacher and the expectations of his or her behaviour suggest that this role is multifaceted and complex. Variability in findings with regard to practice teachers' assisting students in integrating theory and practice as well as differences in the views of students and practice teachers in relation to feedback on practice is evident. As mentioned previously, there is little research exploring views of the role of the practice teacher specifically in social care work which is the aim of this research. Also previous research has used either questionnaires or interviews to collect data while the methodology used in this study combines quantitative and qualitative analysis. It thus permits the documentation and comparison of the aspects of their role the practice teacher participants see as most and least important and the reasoning behind their decisions. 


\section{Methodology}

The methodological approach utilised in this study is that of Q methodology. Q methodology was developed by William Stephenson in 1935 in response to his objections about how factor analysis reduced people to collections of characteristics and provided no information about the individuals themselves (Stephenson, 1936; Watts \& Stenner, 2012). While participants are presented with statements as with traditional attitude inventories Q methodology differs as it is the 'relative agreement and disagreement positioning' of these statements to each other which is captured and analysed as opposed to the 'absolute response' (Lazard, Cadevila \& Roberts, 2011, p.142), thereby overcoming the criticism of attitude research that it does not account for the relationships between viewpoints (Potter, 1996). Hence Q methodology captures people's holistic viewpoints (Watts \& Stenner, 2005; 2012).

Stephenson's aim was to reveal the subjectivity of people in relation to something (in this research their role as a practice teacher) as well as the variation between people's subjectivities. Thus this study explores the subjectivities of participants in relation to the behaviours they could engage in in their role as practice teachers for social care students and compared these subjectivities with each other to find similarity and difference between viewpoints shared by participants.

\section{Data Collection}

Data was collected using the Q technique, which involves an individual sorting statements relating to a topic. The statements ( $\mathrm{Q}$ set) were generated from literature on practice teaching, asking fifteen social care students to write down responses to the statement "the role of the practice teacher involves' and from discussion with a colleague who had been both a social care student and a practice teacher. The statements generated were then examined for repetition with a final selection of thirty-one statements, covering the following areas: 
- Helping the student to link theory and practice

- Providing support and encouragement to the student

- Encouraging self-reflection - knowing self; open-mindedness; individuality in approach to practice; self-assessment

- Providing assistance with college work

- Providing opportunities for learning and monitoring the student's learning

- Ensuing the student was aware of policies and procedures and clients' needs

- Providing opportunities for training and professional development

While in Q methodology the items (statements) to be sorted are known as the Q set the participants are called the $\mathrm{P}$ set.

\section{Participants (P set)}

Prior to approaching potential participants ethical approval was sought and granted by the research ethics committee of the researcher's institution. To meet the expectation that various viewpoints on the topic were included in the sample (Ellingsen, Stǿrksen \& Stephen, 2010) purposive sampling was used. The selection of participants aimed to ensure a variety of backgrounds in relation to social care settings and experience as both a social care practitioner and practice teacher. Details of the sample characteristics are given in Table 1. Potential participants were accessed through previous contact with the researcher in her role as a college tutor, through colleagues who were also tutors and attendees at a practice teacher training programme. One participant was accessed through another participant. Letters providing details of the study and an invitation to take part were sent to potential participants. 
From forty invitations twenty participants agreed to take part and individual interviews were arranged. Prior to the interviews all participants signed a participant consent form explaining their rights to anonymity in publications, confidentiality and withdrawal from the research and giving permission for the interview to be recorded.

Table $1 \quad$ Sample characteristics $(\mathrm{n}=20)$

Characteristics

Number of participants

Gender

Female

14

Male

6

Education

Social care degree

Other degree

Area of current practice

Sensory disability

2

Residential young people

3

Aftercare young people

3

Domestic violence

Addiction service

Mental health service

Intellectual disability

2

Homelessness

Chronic illness

Youth work

Experience in social care (years)

Less than 5

5 to 10

11 to 15

16 to 20

More than 20 
Students supervised

First student 2

2 to 5

6 to 10

11 to 15

16 to 20

More than 30

\section{Procedure}

All participants were emailed a list of the statements a week before the interview date. In the interview participants were presented with the thirty-one statements, each printed on an individual card with a number on the back to facilitate recording. They were first asked to sort the cards into three piles: those they felt were most important to their role as a practice teacher; those they felt were least important and those that were neutral or 'in-between'. After the initial sorting was complete each participant was asked to pick, from the most important pile, the two most important statements in relation to the practice teacher role and to talk about why they considered these the most important. Then they chose and explained the next four more important, then the next six most important. When this was completed participants worked from the least important pile of statements and chose the two least important and explained them, followed by the next four least important and the next six least important. The remaining seven statements were ranked as neutral or in-between. Each participant's ranking of statements was recorded on a score sheet (Figure 1). During the process of sorting participants were given the opportunity to revise the positioning of the statements. Participants were assured that there was no right or wrong answers and the expectation was that there would be differences in their viewpoints. Interviews were fully transcribed and a copy of the transcription sent to each participant. 
Figure $1 \quad$ Score sheet

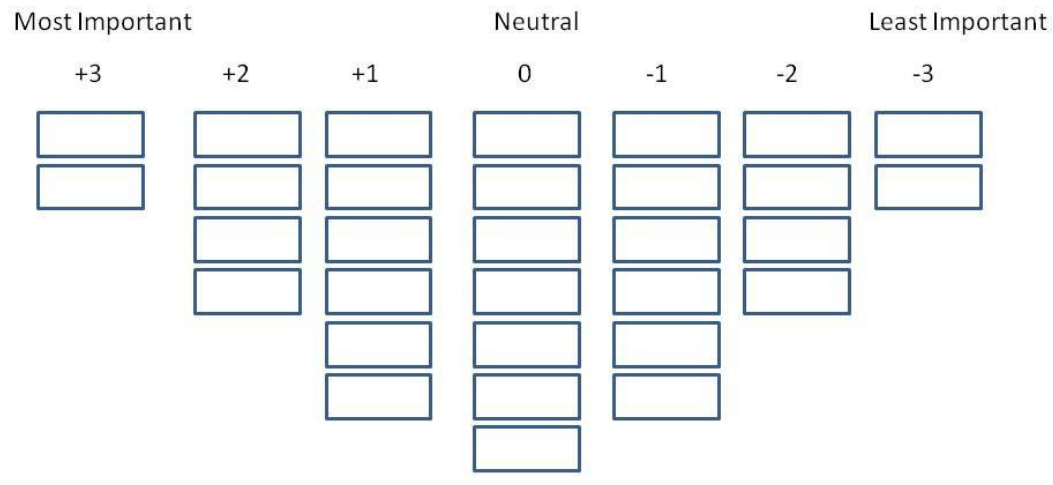

\section{Analysis and Interpretation}

Data from the score sheets were analysed using the computer program PQ Method (Schmolck, 2012). The decision about the number of factors to extract were based on Horst's criterion within the program. Q factor analysis correlates the entire array produced by each participant with every other one thus allowing the determination of commonality in overall viewpoints between participants. The PQ Method program presents the underpinning factors or viewpoints as Q sorts, presented in Table 2. By examining the statements that were most agreed with or disagreed with in each common viewpoint a description of the viewpoint can be given. As the Q sorts were done during a recorded interview the reasoning behind choices of prioritising some behaviours over others the interview transcripts were able to be examined.

\section{Findings}

Although some consensus was evident, particularly with items relating to advising and assisting the student in with college work (See Table 2) two viewpoints (factors) were identified. The elements of agreement will be briefly discussed before outlining the two viewpoints found on the role of the practice teacher. 
1. Identify areas where the student needs to develop in practice.

2. Provide advice about college work.

3. Provide opportunities for learning for the student.

4. Help with linking theoretical frameworks to care practices.

5. Use supervision to link practice to college work.

6. Pass on knowledge about course content.

7. Provide time to discuss how the course is going.

8. Inform the student about the policies and procedures of the organisation.

9. Inform the student about policies and procedures in the area of work.

10. Actively engage in communication with the college.

11. Provide practical feedback on practice.

12. Provide information on professional development.

13. Support the student in balancing study and placement.

14. Be non-judgemental towards the student.

15. Encourage achievement in college work.

16. Support the student to reflect on practice.

17. Be supportive should issues or difficulties arise.

18. Ensure the student takes accountability for his/her practice.

19. Help the student understand how his/her own values, beliefs and feelings affect his/her practice.

20. Discuss the needs of clients.

21. Discuss planned outcomes for clients.

22. Share your own practice experiences.

$-1+0$

23. Facilitate constructive self-criticism.

24. Help the student appreciate his/her own potentials and strengths.

25. Facilitate the student in setting goals in relation to practice needs. 


\section{Areas of Consensus}

All twenty participants ranked the five statements that related to the college programme and academic work in the unimportant range, with the exception of four participants in relation to 'encourage achievement in college work'. Two participants ranked this as neutral and two within the important range. The latter two explained that students needed to know this information to inform practice:

The whole academic piece. Very important in social care.

Have to learn to be able to apply.

Agreement was also found with the importance of the practice teacher providing practical feedback on practice (11); helping students understand how their own values, beliefs, feelings affect practice (19) and the relative unimportance of supporting the student in balancing study and placement (13) and encouraging the student to attend training on specific areas of practice (27). For most participants 'be non-judgemental towards the student' was ranked relatively low with many saying that it didn't need to be specifically mentioned as it was an automatic part of the role. Facilitating the student to critique his or her own practice was ranked negatively in Viewpoint 1 and as neutral in Viewpoint 2 with participants in the first group finding the term criticism as negative and those in the second pointing out the difficulty for students in developing self-monitoring.

\section{Viewpoint 1}

Shared by eleven participants, this viewpoint combines the relevance of knowledge of clients' needs and policies and procedures with open-mindedness to self and practice approaches. Ensuring student accountability but yet providing support is also important. Reference to the centrality of the clients as individuals was frequently made. 


\section{Clients' needs}

The importance of understanding the clients' needs was explained in relation to appreciating the individuality of clients and related to a client-centred approach by five of the eleven participants:

We would have a group with very diverse needs. Very diverse group so it would be important for them to understand that we approach them all quite differently, not as a group.

Also linked to providing a client-centred and non-judgmental approach to practice was helping the student understand how their own values, beliefs and feelings affect their practice $(\mathrm{n}=7)$ :

They might not be aware of their own attitudes towards people in addiction so it gets them really thinking about how their own values, beliefs and attitudes can affect their work practices and how they relate to the clients.

Also mentioned was appreciating that clients have their own belief systems $(n=2)$ or that professional not personal values had to be adhered to $(n=2)$ as well as the impact of past experiences on clients' current behaviours $(n=2)$. Two participants pointed out that a relationship with the student needed to be developed before this discussion took place.

Two participants, one working in an aftercare and one in an intellectual disability service, made the distinction between the needs of clients and their 'wants', while another participant pointed out that the length of a student placement precluded their need to have in depth knowledge of the clients' needs.. A participant working in addiction services noted the importance of students understanding the needs of clients in relation to 'the stigma within society. About the discourses within society to give them some understanding of how that impacts on the client's identity'. She related this to the statement 'help the student understand how their own values, beliefs and feelings affect their practice'. Two participants talked 
about discussing clients' needs in relation to the ideology and ethos of the organisation and the role of the worker:

It is not really just about discussing the needs. It's about understanding that in a context of their own practice. Their role, advocacy and all that.

\section{Policies - ethos and protection}

All participants emphasised the importance of the student knowing the policies and procedures of the organisation although one participant stated that this was also the student's responsibility to be aware of them and one noted that while polices were important they were not the ultimate guide to practice. Most common in the participants' discussions in relation to informing the student of the organisation's policies and procedures were that these formed the framework of practice as they reflected the ethos of the organisation $(n=7)$ :

We have an ethos within the organisation which will be contained within the policies and procedures and when we sign up to work in an organisation we need to understand why that is.

The protection of the clients $(n=4)$ and protection of the student $(n=3)$ was also evident in discussions of the need to inform the student of policies and procedures:

That's partly about protecting their own asses [...]. But as well they are there to protect the young person.

Adhering to the policies and ethos of the organisation was also referred to when some participants were explaining 'help the student understand how their own values, beliefs and feelings affect their practice'. These participants $(n=4)$ referred to students leaving their own views outside the organisation. 


\section{Support and accountability}

The necessity of being supportive to the students as an important element of the practice teacher's role was explained in relation to nature of social care work being challenging and stressful whether it is exposure to violence from clients or the clients' trauma $(n=4)$, conflict with their own feelings $(n=2)$, balancing placement with coursework $(n=2)$ or the inevitable 'dynamics going on in any organisation' $(n=1)$. The importance of students knowing that the practice teacher was available to talk to was mentioned specifically by three participants while three others referred to keeping 'a very close eye on them', and giving 'support rather than the you'll be grand approach'. One participant emphasised the importance of encouraging reflection on difficult experiences and learning from them.

For eight of the eleven participants holding this viewpoint, 'ensure that the student takes accountability for his/her practice' was discussed in relation to the need for the student to acknowledge and learn from errors made. Accountability was discussed in relation to the centrality of the clients $(n=3)$, self-awareness $(n=1)$, the need for caution $(n=1)$ as well as demonstrating trustworthiness $(n=1)$. The other three participants focused on the developmental aspect of being accountable emphasising expectations that taking responsibility is something that the student developed throughout the placement:

They need to be accountable to the level of responsibility they can handle. [...] And unless they're competent there is no point in delegating excessive responsibilities to them, that wouldn't be appropriate to their role or their level of training or ability.

\section{Open-mindedness}

Open-mindedness to different ways of practising was discussed in relation to the need for creativity in the work due to the nature of the work $(n=5)$, the individuality of clients $(n=4)$ as well as differences between college learning and the realities of practice $(n=2)$ : 
An approach might not have been something that they would have done in college. It just might be thinking a little bit differently and just like being aware that you might have to be you know a little bit creative sometimes as well and you're trying out new things and things like that.

As can be seen from Table 2, statements that related to the student's learning and reflection of self and practice were in the 'important' range, although individualised identification of learning needs and goal setting were seen to be of lesser importance as was communication with the college, making links between academic work and practice and the student's future professional development.

\section{Viewpoint 2}

While the first viewpoint emphasised the prominence of the clients of the services the second viewpoint, shared by nine of the twenty practice teachers, focused more directly on the students' reflection on their practice, self and learning. Important aspects of the practice teacher's role involved facilitating reflection on practice and appreciation of students' abilities as well as helping the student set goals, providing learning opportunities and assisting with linking theory to practice.

\section{Reflection}

Reflection on practice was discussed in relation to learning: 'in order to learn you need to reflect. You need to look back' as well as way of transforming 'what you think might be mistakes' into learning opportunities as well as leading to change. Two participants included reflection on theoretical frameworks and appreciating how knowledge of them impacted on practice. Four participants specifically brought in the importance of reflecting on self as well as practice and referred to the statement 'help the student understand how their own values, beliefs and feelings affect their practice' as being related in order to promote a non- 
judgemental approach and avoid defensiveness. Another three participants emphasised the importance of encouraging the student to recognise the positives in their practice while reflecting.

\section{Student and staff development}

Most commonly participants spoke about 'help the student recognise their own potentials and strengths' in relation to providing opportunities for further growth and development $(n=6)$.:

It is important that they appreciate them but also that we use those [strengths]. And that we develop them and that we give feedback on what they have offered.

That students had strengths and staff could learn from them was also discussed $(n=4)$ as students 'see things much differently' and can provide 'an alternative look at how you do your practice' and contribute 'fresh ideas' Two participants related this statement to encouraging the student that $\mathrm{s} / \mathrm{he}$ was able for practice.

\section{Values and self}

That the practice teacher help the student understand the impact of their own values, beliefs and feelings was linked with reflection, as discussed above. In addition it was discussed in relation to professional boundaries $(\mathrm{n}=7)$ with regard to judging clients 'by our own standards', 'see what their baseline is' and with young people acknowledge 'they are not your kids'. Two participants emphasised being open-minded to staff as well.

\section{Learning}

Participants' discussion in relation to their role in 'provide opportunities for learning for the student' fell into two groups, those that emphasised the importance of the practice teacher actively giving the student tasks to do so that learning could happen $(n=6)$ and those $(n=3)$ 
that spoke about learning opportunities not being planned but occurring, with the practice teacher's role being to discuss the learning that happened afterwards. Within the first grouping three participants referred to matching the learning opportunity with the student's capability, two described learning as involving a challenge to the student and one emphasised the importance of discussing the experience after the student had completed the assigned task:

And it might even be a matter of saying simple little things like that person has to go to the hospital this morning. They're going with their keyworker. I'd like you to sort of support that role and you know engage in that process. They're very difficult. They won't sit in A\&E for very long and how are you going to manage that. And give them an opportunity and let them develop it. And then when they come back sit them down and talk it through with them.

For four participants, 'facilitate the student in setting personal goals in relation to practice needs' was seen as being interlinked with 'providing opportunities for learning' and said to be important to 'keep them focused'. Three participants noted that helping the students set goals should be done at the beginning of the placement: 'taking time on this at the beginning is really, really important' so that 'they know what is expected' and 'what they want to gain in terms of knowledge, experience and understanding about myself and the environment'. Two others spoke about helping the student recognise aspects of their practice that needed to change in the present and one about the student beginning to identify their longer term plans in social care work.

\section{Linking theory and practice}

As mentioned above, two participants referred to linking theoretical frameworks to care practice when discussing reflection on practice. Participants spoke about how social care work was underpinned by theories $(n=4)$ : 'if you were to sit down and think about what you 
do on a daily basis I'm sure there is about six or seven theorists that we use their ideas'. They also referred to appreciating the role of different theoretical approaches to practice $(n=3)$ and placement being a setting where students could see theory in action $(n=4)$ : 'It's only when they're on placement that they actually get to see it and identify it.' Part of the role of the practice teacher being to make 'the student aware of the link between college work and the actual practice' was also explicitly mentioned by three participants.

For participants holding the second viewpoint, of secondary importance was facilitating critique of theoretical frameworks and awareness of different approaches to practice. Knowledge of policies and procedures, support and accountability were ranked as neutral.

\section{Discussion}

The aim of this study was to investigate and compare how practice teachers in social care education viewed aspect of their role and the actions they prioritised. Analysis of twenty Q sorts indicated two main viewpoints about the role. Experience in social care practice, having a qualification in social care and experience as a practice teacher did not have an influence on the viewpoint of the role. The first viewpoint emphasises the centrality of the clients within the particular agency and how learning and support for the student was achieved in relation to clients and the agency's policies. The second viewpoint could be considered to go beyond the agency in which they were placed as it emphasised the reflective aspect of the work and the use of theoretical frameworks as well as growing, goal setting and learning. Taken together these could be considered to encapsulate the main tasks of the practice teacher but the breadth of the role, as noted by Davys and Beddoe (2000) could necessitate prioritising some aspects. Contrary to suggestions made by Miehls et al. (2013) participants holding both viewpoints largely agreed on the lack of relevance to their role of them being directly 
involved with the students' academic work and having detailed knowledge of the course content. This suggests that this was viewed as being separate from knowledge of theoretical frameworks. Although not of central importance to either viewpoint the reactions of some participants to the facilitation of constructive self-criticism by the student resonates with that of Bogo et al. (2007). In agreement with their findings participants stated that their preference was to focus on the students' strengths and positive aspects of practice in line with their professional identity and social care values.

The eleven participants who held the first viewpoint show some commonality with the practice teachers in the study of Savya et al. (2003) in that their focus is on the values of social care practice, in particular the obligations to clients of services to meet their individual needs and to protect them. The value of being non-judgemental towards clients (Thompson, 2006) is also evident and discussed in relation to practice teachers facilitating students becoming aware of their own value systems, beliefs and affective reactions impact on how they work with clients as well as developing the values of social care practice. Alongside the students' awareness of their value systems is them learning to appreciate that clients may have different values, which are developed through their experiences and impact on their current behaviour. Professional values are viewed as being embedded in the policies and procedures of the organisation, perhaps suggesting why the students in Wilson et al., (2007) study gave primacy to policies and procedures rather than theory in guiding practice.

Developing a supportive relationship with students was seen as important to discuss direct or vicarious trauma, as noted by Knight (2010), but also to enable students to express conflict between their values and feelings, rather than directly enabling them to learn (Vågstǿl \& Skǿien, 2011). However this was balanced with the student needing to accept responsibility for their own practice, which was related to the core value of client-centred practice For some it was seen as something that developed according to the ability and level 
of the student, suggesting that these participants thought that awareness of the developmental level of the student was important (Karpenko \& Gidycz, 2012).

Finally, central to this viewpoint was open-mindedness to different approaches to practice. Again this was linked to the core value of client-centred practice as well as the need to be creative when working with people. A distinction between what is learned in college and the 'real world' of practice was also made suggesting a theory/practice distinction which could be due to reasons outlined by Dettlaff and Wallace (2003) or Higgins (2014).

Elements of the second viewpoint are more similar to those of social care educators with an emphasis on reflection, linking theoretical frameworks to practice and the student being self-aware (Irish Association of Social Care Educators, 2009). Facilitating students to reflect was seen as important to enable students to improve their practice through reflection on self and by some, a way of integrating theory and practice, in agreement with Staempfli et al. (2012). Reflection was also said to be part of learning the core value of non-judgemental practice and the avoidance of defensiveness when working with clients, as well as maintaining professional boundaries. In line with the focus on emphasising the students' strengths when learning in the literature, reflection on the positives was included by some (Lefevre, 2005). The positive aspects of students' practice and their strengths were also discussed in relation to them being a source of learning for staff as found by others (Globerman \& Bogo, 2003; Barton et al., 2005).

With regard to the practice teacher helping the student to link theory to practice the participants referred to placement as being the site where students could identify the theories that underpin social care practice as well as realise that various theories could inform practice. The participants accepted that, as pointed out by Homonoff (2008), that this was something that students found challenging and needed their assistance with. 
While Fortune et al. (2007) refer to placement as providing opportunities for students to learn and practise professional skills, and providing learning opportunities for students is a part of this viewpoint some participants qualified this. They pointed out that due to the nature of some social care settings it is difficult to plan for all learning. In this case they see the role of the practice teacher to be to help the student recognise the learning that took place when dealing with incidents or observing others deal with them. This suggests that these participants see modelling of behaviour by practitioners as being a source of learning (Leferve, 2005). Others emphasised the importance of ensuring the students set learning goals, both long and short-term, so that individualised learning opportunities could be planned for.

\section{Limitations}

As with all research this study has limitations. As potentially there is always something additional that can be added to a discussion on any topic a $\mathrm{Q}$ set can never be fully complete (Watts \& Stenner, 2005) so while this study utilised many aspects of the role of the practice teacher there are always others there were not included. All participants were asked at the end of the interview what they thought was missing. Two participants, both in the youth work sector, mentioned working in groups. Additionally, though within the parameters of a $\mathrm{Q}$ methodological study, the sample size only consisted of twenty participants. However the purposive choice of participants did lead to a wide range of backgrounds and level of experience.

\section{Conclusion}

While some of the existing literature suggests some differences in the emphases of what the practice placement should provide for the student between educators and practice teachers this study found two main viewpoints held by practice teachers. One prioritises the client and 
the policies of the agency. The second focuses on the reflective learning of the student and the integration of theory.

While limitations are acknowledged this research contributes an insight into how practice teachers in social care view their role in educating students. The findings draw attention to the reality that while students are in placement to learn and develop as future practitioners these services have a duty of care to their clients. However of particular concern for the education of future social care practitioners is, firstly the reluctance to critique the practice of students indicating that practice teachers may need assistance in differentiating between their roles as practitioners and as educators. Secondly, considering that it is through interaction with practitioners that the student begins to develop their professional identity (Miehls et al., 2013) of concern is the low priority given by most of the participants to the part that theoretical frameworks and reflectivity play in informing social care practice. Appreciation of an 'authoritative source of good practice that has legitimacy beyond the workplace' (Sargeant, 2000, p.648) helps avoid 'mechanistic compliance with workplace practices', leading to criticality in relation to the 'way things are done here'. 


\section{References}

Abbott, A.A. \& Lyter, S.C. (1999). The use of constructive criticism in field supervision. The Clinical Supervisor, 17(2), 43-57.

Barton, H., Bell, K. \& Bowles, W. (2005). Help or hindrance? Outcomes of social work student placements, Australian Social Work. 58(3), 301-312.

Bogo, M. (2006). Field instruction in social work. The Clinical Supervisor, 24(1-2), 163-193.

Bogo, M., Regehr, C., Power, R. \& Regehr, G. (2007). When values collide. The Clinical Supervisor, 26(1-2), 99-117.

Brodie, I. \& Williams, V. (2013). Lifting the lid: Perspectives on and activity within student supervision. Social Work Education, 32(4), 506-522.

Brown, S.R. (1996). Q Methodology and qualitative research. Qualitative Health Research, 4, 561567.

Clapton, G., Cree, V.E., Allan, M., Edwards, R., Forbes, R., Irwin, M., Paterson, W. \& Perry, R. (2006). Grasping the nettle: Integrating learning and practice revisited and re-imagined. Social Work Education, 25(6), 645-656.

Davys, A. \& Beddoe, L. (2000). Supervision of students: A map and a model for the decade to come. Social Work Education, 19(5), 437-449.

Dettlaff, A.J. \& Wallace, G. (2003). Promoting integration of theory and practice in field education. The Clinical Supervisor, 21(2), 145-160.

Ellingsen, I.T., Stǿrksen, I. \& Stephen, P. (2010). Q methodology in social work research. International Journal of Social Research Methodology, 13(5), 395-409.

Engelberg, E. \& Limbach-Reich, A. (2015). Prepared enough to practice? Evaluating a study programme in social work. Journal of Social Work. doi: 10.1177/1468017315583172

Fisher, T. \& Somerton, J. (2000). Reflection on action: the process of helping social work students to develop their use of theory in practice. Social Work Education, 19(4), 387-401.

Forte, J.A. \& LaMade, J. (2011). The center cannot hold: A survey of field instructors' theoretical preferences and propensities. The Clinical Supervisor, 30(1), 72-94.

Fortune, A.E., McCarthy, M. \& Abramson, J.S. (2001). Student learning processes in field education: Relationship of learning activities to quality of field instruction, satisfaction and performance among MSW students. Journal of Social Work Education, 37(1), 111-124.

Fortune, A.E. \& Kaye, L. (2003). Learning opportunities in field practica. The Clinical Supervisor, $21(1), 5-28$.

Fortune, A.E., Cavazos, A. \& Lee, M. (2005). Achievement motivation and outcome in social work field education. Journal of Social Work Education, 41(1), 115-129.

Fortune, A.E., Lee, M. \& Cavazos, A. (2007). Does practice make perfect? The Clinical Supervisor, 26(1-2), 239-263. 
Globerman, J \& Bogo, M. (2003). Changing times: Understanding social workers' motivation to be field instructors. Social Work, 48(1), 65-73.

Halton, C. Murphy, M. \& Dempsey, M. (2007). Reflective learning in social work education: Research student experiences. Reflective Practice, 8(4), 511-523.

Higgins, M. (2014). Can practice educators be a 'bridge' between the academy and the practicum? Journal of Practice Teaching and Learning, 12(3), 62-78.

Homonoff, E. (2008). The heart of social work: Best practitioners rise to challenges in field instruction. The Clinical Supervisor, 27(2), 135-169.

Irish Association of Social Care Educators (2009) Practice Placement Manual. Retrieved from http://staffweb.itsligo.ie/staff/pshare/iasce/Placement\%20Manual\%2029mar09.pdf

Joint Committee on Social Care Professionals (2003). Report of Joint Committee on Social Care Professionals, Dublin.

Karpenko, V. \& Gidycz, C.A. (2012). The supervisory relationship and the process of evaluation: Recommendations for supervisors. The Clinical Supervisor, 31(2), 138-158.

Knight, C. (2001). The process of field instruction: BSW and MSW students' views of effective field supervision. Journal of Social Work Education, 37(2), 357-379.

Knight, C. (2010). Indirect trauma in the field practicum: Secondary traumatic stress, vicarious trauma and compassion fatigue among social work students and their field instructors. Journal of Baccalaureate Social Work, 15(1), 31-52.

Lazard, L., Capdevila, R. \& Roberts, A. (2011). Methodological pluralism in theory and in practice: The case for Q in the community. Qualitative Research in Psychology, 8, 140-150.

Lefevre, M. (2005). Facilitating practice learning and assessment: The influence of relationship. Social Work Education, 24(5), 565-583.

Miehls, D., Everett, J., Segal, C., \& du Bois, C. (2013). MSW students' views of supervision: Factors contributing to satisfactory field experiences. The Clinical Supervisor, 32(1), 128-146.

Nye, C. (2007). Dependence and independence in clinical supervision. The Clinical Supervisor, 26(12), 81-98.

O’Neill, E. (2009). Using Professional Supervision in Social Care. In P. Share \& K. Lalor (Eds). Applied Social Care: An Introduction for Students ( $2^{\text {nd }}$ ed.) (pp.182-195). Dublin: Gill \& McMillan.

Potter, J. (1996). Attitudes, social representations and discursive psychology. In M. Wetherell (Ed.). Identities, Groups and Social Issues (pp.119-173). London: Sage Publications Ltd.

Qualifications and Quality Ireland (2014) Social Care Work Award Standards. Retrieved from http://www.qqi.ie/Publications/Social\%20Care\%20Work\%20-\%20Awards\%20Standards.pdf

Raschick M (1998), Improving field education through Kolb learning theory. Journal of Social Work Education, 34(1), 31-43. 
Sargeant, A.V. (2000). An exploratory study of the effects of progression towards National

Vocational Qualifications on the occupational knowledge and care practice of social care workers. Social Work Education, 19(6), 639-661.

Savaya, R., Peleg-Oren, N., Stange, D. \& Geron, Y. (2003). Congruence of classroom and field instruction in social work: An empirical study. Social Work Education, 22(3), 297-308.

Schmolck, P. (2012). PQ Method. Retrieved from http://schmolck.userweb.mwn.de/qmethod/

Simpson, D., Mathews, I. \& Crawford, K. (2014). Finding the perfect match: Pre-placement meetings in social work practice learning. Journal of Practice Teaching and Learning, 12(3), 44-61.

Spence, S.H., Wilson, J., Kavanagh, D., Strong, J. \& Worrall, L. (2001). Clinical supervision in four mental health professions: A review of the evidence. Behaviour Change, 18(3), 135-155.

Staempfli, A, Kunz, R. \& Tov, E. (2012). Creating a bridge between theory and practice: Working with key situations. European Journal of Social Education, 22/23, 60-69.

Stephenson W. (1936). The foundations of psychometry: Four factor systems. Psychometrika 1(3), 195-209.

Thompson, N. (2006) Promoting workplace learning. Bristol: The Policy Press.

Tierney, H. (2011). Mapping fieldwork and supervision practice in the social professions (Part 1). Youth Studies Ireland, 6(1), 18-33.

Tsien, T.B.K. \& Tsui, M. (2007). A participative learning and teaching model: The partnership of students and teachers in practice learning. Social Work Education, 26(4), 348-358.

Vågstǿl, U. \& Skǿien, A.K. (2011). A learning climate for discovery and awareness: Physiotherapy students' perspective on learning and supervision in practice. Advances in Physiotherapy, 13, 7178.

Watts, S. \& Stenner, P. (2005) Doing Q methodology: Theory, method and interpretation. Qualitative Research in Psychology 2, 67-91

Watts, S. \& Stenner, P. (2012). Doing Q Methodological Research: Theory, Method and Interpretation. London: Sage Publications.

Wilson, G., Walsh, T. \& Kirby, M. (2007). Reflective practice and workplace learning: The experience of MSW students. Reflective Practice, 8(1), 1-15.

Wilson, G., O'Connor, E., Walsh, T. \& Kirby, M. (2009). Reflections on Practice Learning in Northern Ireland and the Republic of Ireland: Lessons from Student Experiences. Social Work Education 28(6), 631-645. 